\title{
A PUBLICIDADE ENGANOSA NO NEGÓCIO CONSUMERISTA: CONSIDERAÇÕES ACERCA DE SEUS REFLEXOS JURÍDICOS
}

\author{
Mariana Faria Filard ${ }^{1}$ \\ Thandra Pessoa de Sena ${ }^{2}$
}

\begin{abstract}
RESUMO: A publicidade consiste em forma de comunicação entre fornecedor e consumidor, para comercialização de produtos e serviços disponibilizados no mercado, com estratégia persuasiva, visando influenciar o comportamento dos consumidores. O Código de Defesa do Consumidor supriu a omissão legislativa existente, proibindo as publicidades enganosa e abusiva, visto que a regulamentação pelo Conselho Nacional de Autorregulamentação Publicitária (CONAR), não possuía força coercitiva para punir aqueles que infringiam os postulados, bem como normas de ética da publicidade. O objetivo deste trabalho é evidenciar os reflexos jurídicos da publicidade enganosa, utilizando-se o método de investigação indutivo, com pesquisa bibliográfica.
\end{abstract}

Palavras-Chaves: Direito do Consumidor; Publicidade Enganosa; Consumidor; Publicidade Abusiva; Negócio Consumerista.

\section{THE DANGEROUS ADVERTISING IN THE CONSUMERIST BUSINESS: CONSIDERATIONS ABOUT ITS LEGAL REFLECTIONS}

\begin{abstract}
Advertising consists of a form of communication between supplier and consumer, for the marketing of products and services made available in the market, with persuasive strategy, aiming to influence consumer behavior. The Code of Consumer Protection amended the existing legislative omission by prohibiting misleading and abusive advertising, since the regulation by the National Council for Self-Regulatory Advertising (CONAR) did not have coercive force to punish those who violated postulates as well as ethical standards advertising. The objective of this work is to highlight the legal reflexes of misleading advertising, using the method of inductive research, with bibliographical research.
\end{abstract}

Keywords: Consumer Law; Misleading publicity; Consumer; Advertising Abusive; Consumerist Business.

\footnotetext{
${ }^{1}$ Doutoranda em Ciência Jurídica UNIVALI/SC, Mestra em Ciência Jurídica pela UNIVALI/SC, Especialista em Direito Processual Civil pela UFAM e Especialista em Direito das Relações Sociais pelo CIESA/AM. Graduada em Direito pela UNINILTON LINS/AM e atualmente Assistente Jurídica do Tribunal de Justiça do Estado do Amazonas. (marianafilard@gmail.com)

${ }^{2}$ Mestra em Ciência Jurídica pela UNIVALI/SC, Especialista em Direito Processual Civil. Graduada em Direito pelo CIESA/AM. Professora do Curso de Direito da Faculdade Martha Falcão Wyden/AM. (thandrasena@gmail.com)
} 


\section{INTRODUÇÃO}

A sociedade contemporânea possui uma importante característica que é a comunicação. Por meio dela, as pessoas recebem as últimas notícias sobre acontecimentos, sobre pessoas, produtos e serviços. Outra característica marcante desta sociedade atual é o intenso desejo de consumir, sejam bens indispensáveis para a subsistência ou supérfluos, importantes para a manutenção de seu status social. No entanto, para que a sociedade possa saciar o seu desejo consumidor, mister que ela tenha conhecimento sobre quais produtos ou serviços estão no mercado à sua disposição, suas características, bem como seus riscos.

Esta tarefa é destinada publicidade. Entretanto, a publicidade não é apenas informação, mas persuasão. Um anúncio publicitário ao ser veiculado, possui o objetivo não apenas de informar o consumidor, mas promover a venda do produto que está sendo anunciado.

O trabalho da publicidade será então conseguir estimular essas predisposições, a fim de induzir o consumidor a realizar determinada conduta, para que seja tomada uma decisão no sentido da compra (MORAES, 2001)

Não há dúvidas sobre a importância do fenômeno publicitário e de sua relação com a sociedade de consumo atual, pois os fornecedores, ao utilizarem a publicidade para estimular a demanda de produtos e serviços, muitas vezes cometem abusos, influindo nas decisões de compra dos consumidores e levando-os inclusive ao erro e à situações que os ponham em risco.

Tendo em vista o poder de persuasão da publicidade, necessária se tornou sua regulação em favor dos mais frágeis nas relações de consumo, ou seja, os consumidores.

A promulgação do Código de Defesa do Consumidor, em 1990, encerrou a era exclusiva do Conselho Nacional de Autorregulamentação Publicitária (CONAR), instituindo um sistema misto de controle da publicidade e suprindo a lacuna existente em nossa legislação quanto a esta questão. O Código de Defesa do Consumidor deu especial importância à transparência da informação aos consumidores, proibindo a publicidade enganosa e abusiva, e estabelecendo sanções no âmbito administrativo, civil e penal.

Este trabalho tem por finalidade promover um estudo sobre a publicidade enganosa à luz do Código de Defesa do Consumidor e seus reflexos jurídicos, retratando a nova realidade doutrinária e jurisprudencial, utilizando-se o método de investigação indutivo, com pesquisa bibliográfica.

Primeiramente, foi realizada uma breve exposição sobre os aspectos históricos da 
publicidade e a conceituação de publicidade, constando a diferenciação entre publicidade enganosa, abusiva e abuso na publicidade infantil.

Demonstrou-se como a publicidade detém o poder de persuadir o consumidor, e como a publicidade tornou-se uma forma dominante de comunicação e um elemento decisivo da cultura que nos molda.

Discutiu-se a preocupação do direito com a publicidade e a contemplação dos direitos dos consumidores, derivada da promulgação do Código de Defesa do Consumidor, permitindo a regulação da publicidade enganosa.

E por fim, apresentamos uma conclusão, inserindo os motivos relevantes, pelos quais a publicidade passou a tomar parte, de forma definitiva em nosso sistema de produção, sugerindo, ainda, formas de controle da publicidade enganosa, evitando que as mensagens publicitárias sejam instrumentos de distorção para a escolha dos consumidores.

\section{ANTECEDENTES HISTÓRICOS DA SOCIEDADE DE MASSA E DA PUBLICIDADE}

Bauman (2007) define a modernidade como "líquida", fluida, impermanente, de forma que a mudança é constante, nunca tem um término. Caracteriza ainda, a sociedade líquida pela incapacidade de manter a forma. Nossas instituições, quadros de referência, estilos de vida, crenças e convicções mudam antes que tenham tempo de se solidificar em costumes, hábitos e verdades. Isso é o que ocorre com a sociedade atual.

Segundo Faria (2002), podemos entender a publicidade como um dos fenômenos mais intrigantes da atualidade, uma vez que atua na construção da vontade do consumidor. Seu desenvolvimento se deu conjuntamente com a expansão do capitalismo. Na sociedade préindustrial, a produção era manufatureira ou artesanal. A comunicação entre o fornecedor e o consumidor era feita pessoalmente, circunscrita à fase de aquisição, referindo-se a detalhes do produto. $\mathrm{O}$ fornecedor tinha uma reputação no mercado e suas informações eram uma garantia de qualidade dos bens ofertados.

Enquanto atividade organizada, a arte publicitária é recentemente em seu aspecto comercial. No aspecto ideológico, é tão velha quanto o homem, pois, desde que esse desceu das árvores e passou a ter consciência de si, desenvolveu um discurso ideológico visando a dominação do semelhante. Na verdade, somente se pode falar de 
publicidade comercial propriamente dita após o surgimento da imprensa, apontando os pesquisadores a Inglaterra como berço desta arte. (JACOBINA, 2002)

A partir da revolução industrial o capitalismo ganhou novos contornos com o surgimento da sociedade de massa, possibilitando a oferta de uma gama de produtos ao mercado. Os bens passaram a ser produzidos não mais para atender as necessidades dos particulares, mas destinados a consumidores indeterminados.

A estratégia da especialização flexível permitiu uma produção programável de produtos variados, não padronizados, singularizados e dirigidos a consumidores não específicos. A redução de custo dos transportes e das comunicações levou as empresas a organizarem-se em nível global e constituírem grupos de sociedades surgidos a partir de processos de incorporações, fusões, aquisições, cisões, transferência de ativos. Isto possibilitou a estas empresas, uma melhor adaptação à volatilidade dos mercados e à coordenação de atividades realizadas por suas diferentes unidades espalhadas pelo mundo. Atualmente existem empresas globais operando por meio de inúmeras filiais com um faturamento superior ao produto interno bruto (PIB) de muitos países.

Concomitantemente a este processo, ocorreu à formação de um sistema de persuasão da comunicação publicitária que molda necessidades, gera desejos, seduz os consumidores e que são tão ou mais importante que o próprio sistema de produção de bens, já que, sem ele, as vendas não se concretizariam.

É este, então, o importante papel da publicidade no sistema industrial atual. Ela permite a comunicação entre as empresas e os consumidores e, a sua utilização visando o convencimento do consumidor, lhe confere um grande poder social de forma a ser considerada um verdadeiro instrumento de controle social.

A ideia de tutelar os direitos dos consumidores, segundo Efing (1999), datam do Brasil Império, mas somente adquiriu status de matéria constitucional em 1934. O Código de Defesa do Consumidor foi promulgado em 11 de setembro de 1990 e entrou em vigor seis meses depois, ou seja, em 11 de março de 1991. Sua promulgação ocorreu em decorrência de mandamento constitucional, justamente por se compreender a importância do consumo e a proteção dos consumidores, naturalmente vulneráveis, nesta relação.

A publicidade, cujo objetivo é estimular a aproximação entre o consumidor e os produtos e serviços a serem comercializados, não poderia deixar de fazer parte desta legislação 
protetiva. Chaise (2001) diz que a Publicidade é toda forma de comunicação e informação difundida com objetivo direto ou indireto que juntamente com o consumidor promove a aquisição de um produto ou serviço.

Ressalta-se que deve ser controlada por se tratar de um instrumento que possui um forte apelo emocional e ter características de persuasão, de atração, de estímulo, de convencimento que pode colocar em risco os consumidores, estimulando comportamentos antissociais ou induzir em erro sobre falsas vantagens atribuídas pelos fornecedores aos produtos e serviços divulgados.

Para Lopes (1992), as empresas no afã de salientar as qualidades dos produtos podem levar à distorção, para as quais o legislador tem de voltar sua atenção. Isso é o que explica a preocupação do direito com a publicidade, pois o alcance deste instrumento pode vir a causar danos patrimoniais e morais de grandes proporções, eis que seu reflexos, como regra, são difusos e coletivos, embora com repercussão na esfera privada de cada consumidor. Seus riscos são sociais e seus danos em série.

\subsection{A Constituição Federal, O Código de Defesa do Consumidor e a Importância da Publicidade no Consumo}

No Brasil a publicidade carecia de uma regulamentação sistematizada. $\mathrm{O}$ autocontrole exercido pelo CONAR (Conselho de Autorregulamentação Publicitária) se mostrou ineficiente em face da própria natureza jurídica desse Conselho: uma sociedade civil integrada majoritariamente por publicitários, por adesão espontânea, e cuja competência estatutária não vai além da imposição de penas simbólicas como advertência.

A Constituição Federal também previu a proteção do indivíduo, tendo erigido o direito do consumidor a direito constitucional fundamental, no Título II - Direitos e Garantias Fundamentais, a obrigação de o Estado promover a defesa do consumidor e o reconhecimento de um novo sujeito de direitos, os consumidores, individual ou coletivamente, e de compromissos do Estado para a sua proteção, assegurando-lhes a titularidade de direitos constitucionais fundamentais (artigo $5^{\circ}, \mathrm{XXXII}$, da CF), bem como uma legislação codificada especial (artigo 48, do ADCT) e, ainda, a consagração da defesa do consumidor como princípio da Ordem Econômica (artigo 170, V, da CF). 
Conforme explana Cláudia Lima Marques (2009) trata-se de um ramo de direito interno de cada país que visa proteger com normas de ordem pública e interesse social um sujeito de direitos, o consumidor, considerado mais fraco nas suas relações de direito privado.

O Código de Defesa do Consumidor supriu a lacuna existente em nossa legislação, através da instituição de normas de ordem pública que tem por objetivo a proteção dos consumidores. O novel Código, na esteira da evolução doutrinária e jurisprudencial, estabeleceu novos direitos e, por consequência, novos deveres; oportunizando inéditas leituras de novos princípios (como o da função social dos contratos e da boa-fé objetiva) - e releitura de antigos também (como o da força obrigatória dos pactos - pacta sunt servanda).

Não proíbe a publicidade, visto ser ela, ineliminável da sociedade de consumo, mas a torna fonte de obrigação (art. 30, do CDC), impondo deveres ao fornecedor que delas se vale (art. 36 e 38, do CDC) e proibindo a publicidade enganosa e abusiva. Optou, portanto, em tratar distintamente as duas espécies de patologias de comunicação de massa, tutelando diferentes bens jurídicos. Prevê ainda, efeito e sanções administrativas e penais correlacionadas à publicidade.

Nas palavras de (BITTAR, 1992):

[...] deve-se, esclarecer que a publicidade visada pelo regime repressivo do Código de Defesa do Consumidor não é a inserida em mensagem honesta e inteligente, mas a que se expressa com falseamento da verdade, ou com a ilaqueação da boa-fé do destinatário, ou com desrespeito a valores essenciais do relacionamento social.

Para pleitear a proteção do Código, não se faz necessário que o consumidor tenha adquirido o produto ou serviço, bastando sua exposição à mensagem publicitária que potencialmente possa vir a causar um dano, de caráter coletivo ou difuso, pouco importando o público ao qual foi dirigida.

Bauman (2007) vê o ser humano transformado numa estrutura flexível programável para o consumo. As interações sociais e os laços afetivos estão cada vez mais fracos, devido à modernidade líquida. Tudo passa a ter um cunho econômico, focalizando a materialidade nas relações.

Não há como negar: a função explicitamente ideológica que a publicidade exerce, assim como a de outras manifestações culturais, a serviço das classes e dos grupos econômicos 
que detém a hegemonia política e/ ou econômica na sociedade de massa e na economia de mercado.

A função da publicidade consiste em informar o consumidor sobre os bens e serviço disponíveis no mercado, ressaltando suas qualidades com o objetivo de convencer as pessoas a adquirí-los.

A expansão da publicidade acompanhou o processo de concentração econômica e a transformação do mercado alterando seu objetivo que era de informar para converter-se em um instrumento de persuasão.

Como bem reconheceu Amaral (1991, p. 39), ao analisar a publicidade constatamos que a sua grande relevância está na capacidade de proporcionar a criação artificial de necessidades e sobrevalorização de produtos ou serviços nem sempre adequados, o que permite eleger uma produção como objetivo primordial da atividade econômica. Isto confere à publicidade o poder de alterar comportamentos sociais à medida que influencia os destinatários a agir de uma determinada maneira, atuando como instrumento capaz de interferir nas escolhas individuais, permitindo o controle social.

Chaves (1999) considera que a ideologia dos anúncios catalisa interesses comuns de diferentes indivíduos, fazendo com que os ideais peculiares do capitalismo sejam os mesmos ideais populares e dos consumidores. A publicidade, portanto, faz do consumo um ideal de existência.

A flexibilização das regras sociais, econômicas e políticas no mundo atual contribui para enfraquecer o poder pré-estabelecido e criar um regime de insegurança social. Estratégias da publicidade transformam-se em um remédio para a crise da pós-modernidade.

A publicidade tornou-se uma forma dominante de comunicação e um elemento decisivo da cultura que nos molda. É cada vez mais frequente a utilização de imagens que não vendem produtos ou serviços, mas atitudes, sonhos, desejos de forma a estimular comportamentos.

Para Bauman (2007) analisa que o consumo, ou aquilo que se convencionou chamar cultura de consumo, nota que o poder de atração dos objetos é diretamente proporcional à potência que levam consigo. Sob esse ponto de vista, a habilidade de qualquer objeto de consumo em conquistar corações e mentes está calcada sobre suas pretensas capacidades, 
potências, sejam elas passíveis de realização, ou não. O que motiva o consumo, ao cabo, não é o objeto em si, ou sua utilidade mais pragmática, mas sua capacidade potencial e aparente de realizar algo que esteja além de suas condições imediatas. De fato, o que se percebe é o desejo do consumidor de que os objetos ultrapassem a si mesmos, em suas possibilidades imanentes.

Bauman (2011) ainda nos lembra que em nossa sociedade de consumidores, o ímpeto de reproduzir o estilo devida hoje recomendado pelas últimas ofertas de mercado e elogiado por porta-vozes contratados e voluntários desses mesmos mercados (e, por conseguinte, a compulsão para se revisar de modo perpétuo a identidade e a persona pública) não são mais associados à coerção externa (e, assim, ofensiva e aborrecida); esse ímpeto tende a ser percebido, em vez disso, como mais uma manifestação e mais uma prova da liberdade pessoal.

A ideologia de nossa sociedade está fortemente comprometida com o individualismo e com a economia de mercado e reconhece, cada vez mais, os valores da autoindulgência (perdão), incentivada pela permissividade (ato de permitir) organizada entorno dos prazeres do consumidor, em detrimento do controle dos impulsos. A publicidade alimenta a cultura de massa do hedonismo, cercando o consumidor de imagens onde o conflito não existe, as pessoas são felizes e, quando têm um problema, conseguem transformar sua realidade, como num passe de mágica, através de um produto "maravilhoso".

Em um país como o Brasil, marcado por expressiva desigualdade social, alta concentração de renda, ausência de crescimento econômico e com uma economia mutável, onde a maioria da população não têm condições de consumir, e possível afirmar que a publicidade é um fator que contribui para o incremento da violência. A regulação da sociedade pela noção de consumo como condição de acesso à plenitude da vida resulta em consumidores fanatizados pela indústria cultural.

\section{NEGÓCIO CONSUMERISTA E AS ESPÉCIES DE PUBLICIDADE}

A publicidade que desrespeita a imposição legal de veracidade, fere o interesse de toda a coletividade de pessoas a ela exposta, determináveis ou não, e que são equiparadas ao conceito de consumidor nos termos do art. 29, do Código. A regra do sistema consumerista instituído é a de sua proibição, independentemente de ter causado prejuízos efetivos aos consumidores. Isto

Rev. de Direito, Globalização e Responsabilidade nas Relações de Consumo | e-ISSN: 2526-0030 | Porto Alegre | v. 4 | n. 2 | p. $129-144$ | Jul/Dez. 2018 
porque, ela é vedada enquanto atividade objetivamente considerada, para proteção do consumidor, e não para a punição do comportamento do anunciante.

Para sua caracterização, não se faz necessário aferir se houve dolo ou culpa do anunciante. Ela gera um dano moral para a coletividade, na medida em que ofende valores seus, sendo passível de reparação. O Código dispõe ainda, no parágrafo único, do art. $7^{\circ}$, a responsabilidade solidária e constatada a culpa, as sanções civis, administrativas e penais podem se dirigir a um ou todos que participaram da elaboração da mensagem publicitária.

É importante frisar, que Consumidor é qualquer pessoa que adquire um produto ou que contrata um serviço, para satisfazer suas necessidades pessoais ou familiares. Também é considerado consumidor as vítimas de acidentes causados por produtos defeituosos, mesmo que não os tenha adquirido (art. 17, CDC), bem ainda as pessoas expostas às práticas abusivas previstas no Código do Consumidor, como, por exemplo, publicidade enganosa ou abusiva (art. 29, CDC).

A propósito, salienta Almeida (2006) que o fornecedor é o responsável pelo fato do produto ou do serviço (art. 12, CDC), pelo simples fato de que o fabricante, o produtor, o construtor e o importador são os autores da colocação no mercado do produto defeituoso, sendo natural, portanto, que assumam os riscos dessa conduta e arque com os encargos decorrentes da reparação de danos das atividades que lhes são próprios, como projeto, fabricação, construção, montagem, manipulação ou acondicionamento, além daquelas decorrentes de insuficiência ou inadequação de informação sobre utilização e riscos dos produtos e serviços.

Em todos os casos a responsabilidade se mostra clara e evidente, tendo em vista a estreita ligação entre o fornecedor e o produto ou serviço.

A publicidade, em si, é licita. Mas não pode negar que seu maior objetivo não é informar, mas induzir a compra. Por isso, deve pautar-se pelos princípios básicos que norteiam as relações entre fornecedores e consumidores, especialmente o da boa fé. As relações de consumo, mesmo na sua fase pré-contratual, devem guiar-se pela lealdade e pelo respeito entre as partes.

Vale recordar os ditames do art. 36 do Código de Defesa do Consumidor:

Art. 36. A publicidade deve ser veiculada de tal forma que o consumidor, fácil e imediatamente, a identifique como tal. 
Parágrafo único. O fornecedor, na publicidade de seus produtos ou serviços, manterá, em seu poder, para informação dos legítimos interessados, os dados fáticos, técnicos e científicos que dão sustentação à mensagem".

O Código de Defesa do Consumidor, partindo da premissa da lealdade, proíbe a publicidade enganosa no art. 37 , caput e $\S \S 1^{\circ}$ e $3^{\circ}$, verbis:

É enganosa qualquer modalidade de informação ou comunicação de caráter publicitário, inteira ou parcialmente falso, ou, por qualquer outro modo, mesmo por omissão, capaz de induzir em erro o consumidor a respeito da natureza, características, qualidade, quantidade, propriedades, origem, preço e quaisquer outros dados sobre produtos e serviço.

Este dispositivo reconhece o direito - de ordem pública - do consumidor não ser enganado por qualquer informação inteira ou parcialmente falsa ou até mesmo verdadeira, capaz de induzí-lo em erro a respeito dos produtos ou serviços. O Código assim o fez, por entender que esta atividade por si só já viola um direito básico do consumidor e das pessoas a ele equiparadas que é o da veracidade da informação publicitária (art. 6º, III, do CDC), necessário para que o consumidor possa fazer sua escolha de forma livre e consciente.

A publicidade abusiva encontra-se descrita no $§ 2^{\circ}$, do artigo 37, do Código de Defesa do Consumidor:

É abusiva, dentre outras, a publicidade discriminatória de qualquer natureza, a que incite à violência, explore o medo ou a superstição, se aproveite da deficiência de julgamento e experiência da criança, desrespeita valores ambientais, ou que seja capaz de induzir o consumidor a se comportar de forma prejudicial ou perigosa à sua saúde ou segurança.

Há divergência na doutrina quanto aos significados de publicidade e propaganda. A publicidade visa o negócio, o comércio. Já, por sua vez, a propaganda possui caráter ideológico, político. Em resumo, a comunicação tem por escopo transmitir uma mensagem para o consumidor, seja sob a forma de propaganda de produtos ou de serviços (publicidade) seja sob a forma de propaganda ideológica ou política.

Podemos ainda, diferenciar a propaganda abusiva da enganosa por esta aproveitar o medo ou a superstição para que o consumidor se comporte de forma prejudicial à sua saúde ou segurança, visto que essas campanhas trazem danos diretos ou indiretos para a vida dos consumidores. Dessa forma, a publicidade abusiva equipara-se ao abuso de direito, visto que se 
veste de um manto de falsa legitimidade para violar direitos dos consumidores e da sociedade ao extrapolar os limites estabelecidos pela lei.

Ainda, há que se esclarecer que os conceitos de publicidade enganosa e abusiva não se confundem, podendo uma publicidade ser perfeitamente honesta no que se refere à sua veracidade, e ainda sim ser ofensiva a qualquer valor social, ou moral.

Frequentemente, empresas ligadas a produtos infantis são denunciadas por abuso. Os casos estão ligados à linguagens não infantis, da inserção precoce no mundo adulto ou relacionados com uma proposta de necessidade de aquisição dos produtos.

No rol dos direitos fundamentais, a Constituição Federal, em seu artigo 227, consagra a proteção integral às crianças e adolescentes, com redação dada pela EC 65/10:

Art. 227. É dever da família, da sociedade e do Estado assegurar à criança, ao adolescente e ao jovem, com absoluta prioridade, o direito à vida, à saúde, à alimentação, à educação, ao lazer, à profissionalização, à cultura, à dignidade, ao respeito, à liberdade e à convivência familiar e comunitária, além de colocá-los a salvo de toda forma de negligência, discriminação, exploração, violência, crueldade e opressão. (Redação dada Pela Emenda Constitucional no 65, de 2010)

O Estatuto da Criança e do Adolescente nos traz de forma detalhada quais são os direitos fundamentais a que ele faz menção expressa. Claro que além dos enumerados, todos os demais referentes a todo ser humano, também pertencem às crianças e adolescentes.

\section{RESPONSABILIDADE CIVIL DO FORNECEDOR QUANTO À PUBLICIDADE ENGANOSA}

No Direito Civil, reporta-se a teoria dos contratos, na qual se verifica o contrato de consumo e/ou adesão, também abordando a oferta ao público, conforme o art. 429 do Código Civil de 2002, pois a publicidade é uma forma de veicular oferta e obriga anunciante-fornecedor a uma proposta mediante requisitos essenciais ao contrato, salvo se resultar das circunstancias ou dos usos. Assim, podemos afirmar que "A publicidade integra o contrato e obriga o fornecedor a cumprir o que foi noticiado" (arts. 30 e 67, Código de Defesa do Consumidor).

O direito à informação foi bastante ressaltado no CDC (arts. $4^{\circ}, 6^{\circ}$, II, III e IV, e 51, IV, $\S 11^{\circ}$, I e II). Trata-se, de fato, do princípio da transparência (arts. 6. ${ }^{\circ}$, III, 31 e 46), que integra, na interdisciplinaridade com o Direito Civil, o princípio da boa-fé objetiva (arts. 113 e 
422 do CCB), ou seja, qualquer que for a norma aplicada (consumerista ou civil), a mens legis e a mens legislatoris que regem o art. 36 devem ser analisadas sob o enfoque constitucional e consoante as cláusulas gerais contidas no CDC.

BRAGA NETTO (2014) entende que o princípio da informação biparte-se em dois núcleos: o direito de ser informado e o dever de ser informado.

Devem ser observados, então, não só na fase contratual, mas também na fase précontratual e até pós-contratual, o princípio da transparência e o dever de informação (arts. 6. ${ }^{\circ}$, III, 31 e 46). A existência apenas do simples consentimento ou da vontade declarada (teoria declarativa) não é o suficiente, na atualidade, para obrigar o consumidor ao cumprimento de uma obrigação pactuada. No que se refere às teorias subjetivas do contrato, a voluntarista é a que mais se aproxima da equidade e da justiça contratual, pois nas declarações de vontade será observada a real intenção (elemento volitivo interno) dos contratantes, ao invés do sentido literal da linguagem. Outra não é a diretriz fixada pelo CDC e pelo CC/02. Recorda-se que a ausência do elemento animus mancha, eiva o contrato de nulidades das mais diversas.

Logo, conclui-se que a fase pré-contratual é tão importante quanto a vontade declarada, a conclusão e a execução do contrato. No período transcorrido durante aquela primeira etapa, torna-se preponderante a análise do contexto histórico vigente para apurar a formação da vontade interna/real e as necessidades do consumidor. A conjugação desses fatores (realidade e vontade) delimitará o contrato e suas cláusulas. Se há falha na prestação de informações pertinentes ao produto ou ao serviço, a vontade declarada do consumidor estará viciada.

Por isso, o princípio da transparência e o dever de informação (arts. $4 .^{\circ}, 6^{\circ}{ }^{\circ}$, III, 31, 46 e 51, I, do CDC) revelam-se essenciais em uma relação consumerista. Além de constituírem-se em mero elemento formal, ambos interferem na essência do negócio jurídico, do contrato, pois se ignorados ensejam em vício de consentimento.

Os novos direitos delineados pelo CDC e pelo CC/02 têm raízes profundas surgidas a partir dos princípios da transparência, da função social dos contratos e da boa-fé objetiva - três das mais importantes cláusulas gerais da novel codificação. Em plena época dos contratos de adesão ("em massa", standard), afiguram-se praticamente impossíveis a correta e completa informação, a transparência e a discussão de cláusulas contratuais, fato que por si só já repele a equidade e a liberdade contratual e coloca o consumidor-aderente em posição de inquestionável inferioridade. 
Além do mais, não se pode perder de vista que os pactos devem primar pela solidariedade, pelo equilíbrio das prestações, pelos valores sociais, econômicos e morais e, primordialmente, pelo respeito ao consumidor e à dignidade da pessoa humana (arts. $1^{\circ}$, III; 3. ${ }^{\circ}$, I, e 170 , III, V, VII da CF/88).

É importante notar que, por ser de caráter mercantil, pois seu objetivo é o lucro, a atividade publicitária deve respeitar as práticas comerciais de concorrência e lealdade preconizadas pelo Direito Econômico e Comercial. Os abusos ou excessos cometidos pela publicidade são tratados também no Direito Penal e Penal Econômico, classificado os tipos penais, responsabilizando e sancionando os infratores pelas infrações e danos causados ao consumidor. O exemplo, o CDC também se expressa quanto as infrações penais nos arts. 6, 67, 68 e 69, e tem tratado específico da regulação da prática publicitária no art. 29 a 38, dispondo sobre as práticas de oferta, definição e diretrizes da atividade publicitária.

Quanto à forma de regulamentação privada estão o Código de Ética dos Profissionais da Propaganda e o Código Nacional de Autorregulamentação, que consta de práticas e princípios os quais são assegurados através da criação do CDC. A Constituição Federal de 1988 cuidou da publicidade do serviço público no art. 37, CF/88, que regula, entre outros, o princípio da moralidade ( $\$ 1^{\circ}$ art. 37, CF/88). E tratou da publicidade de produtos, práticas e serviços no capítulo comunicação social (inciso II do $\S 3^{\circ}$, art. 220, CF/88), guardando regra especial para anúncios de bebidas alcoólicas, agrotóxicos, medicamentos e terapias ( $\$ 4^{\circ}$ do art. 220, CF/88). Destarte, o inciso II do $\S 3^{\circ}$ do art. 220, CF/88 referido, estabelece que se deve proteger a pessoa e a família contra a publicidade nociva à saúde e ao meio ambiente.

Evidencia-se aí a importância dos direitos fundamentais, especificamente na questão da liberdade de expressão e dignidade da pessoa humana no Estado Democrático de Direito. A liberdade de expressão é um direito fundamental, art. 5 $, \mathrm{IX}, \mathrm{CF} / 88$ e a dignidade da pessoa humana é um princípio fundamental, art. $1^{\circ}$, III, CF/88, descritos na doutrina como relativos. A Constituição estabelece limites aos direitos fundamentais, é o caso do fenômeno da colisão de direitos fundamentais, que consiste no exercício lícito de um direito fundamental sobre o campo de proteção de outro direito fundamental (CANOTILHO, 1993).

Corrobora-se nas jurisprudências brasileiras a repressão a qualquer abuso do direito à livre manifestação do pensamento, concedendo direito de resposta, às responsabilizações civil ou penal, inclusive com a proibição de publicações lesivas a outros direitos fundamentais. 


\section{CONCLUSÃO}

As relações de consumo configuram-se um negócio, nas quais, fornecedor e consumidor, pactuam regras sem no entanto, muitas vezes observar que direitos fundamentais podem estar sendo violados. O consumidor, parte vulnerável nesta relação, frequentemente sofre a influência de publicidades enganosas e abusivas, utilizadas pelo fornecedor sob o argumento do direito constitucional da liberdade de expressão.

Ocorre que, esta forma de comunicação atinge público indeterminado possuindo papel importante na relação de consumo, na sociedade de massa, movimentando o mercado para atrair consumidores à utilização de produtos ou serviços.

Para tanto, esta deve ser devidamente fiscalizada para que não haja abusos ou excessos, equilibrando as relações consumeristas.

Resta claro que o consumidor possui direito à informação clara e precisa e, esta tornase elemento essencial para conheça o produto e o adquira, utilizando-o de forma adequada sem colocar em risco sua saúde, atendendo finalmente suas necessidades pois é por este instrumento de comunicação, que tais informações são repassadas ao destinatário final do consumo.

Dessarte, a publicidade não é considerada apenas informativa, mas também como forma de indução e persuasão para aquisição de produtos ou serviços e, caso seja transmitida com algum vício, em desconformidade com os preceitos legais, há que se coibir por meio do controle estatal e do esforço de cada consumidor em reclamar perante os órgãos responsáveis pelas práticas abusivas toda vez que sentir lesado, para que haja punição e correção dos fornecedores infratores.

Observamos ainda que, o Código de Defesa do Consumidor veio preencher lacunas existentes no controle já efetuado pelo Conselho Nacional de Autorregulamentação Publicitária (CONAR).

No entanto, para que se realize este controle, o consumidor necessita de educação e informação, de conhecer os seus direitos, de forma a garantir que nessa era pós-moderna, o consumo não seja demasiado, e a publicidade atinja seus fins de forma lícita, promovendo a propagação correta da informação. Nessa perspectiva, entende-se que o consumo não pode ser tido como algo prejudicial, mas que seja exercido observando-se os direitos fundamentais e a dignidade da pessoa humana, sem os quais o ser humano não se reconhece. 


\section{REFERÊNCIAS}

AMARAL JÚNIOR, Alberto do. O princípio da vinculação da mensagem publicitária, São Paulo: RDC, 1995.

BAUMAN, Zigmunt. Vida de consumo. Buenos Aires: Fondo de Cultura Económica, 2007.

BAUMAN, Zygmunt. Does Ethics Have a Chance in a World of Consumers?

Tradução autorizada da primeira edição inglesa, publicada em 2008 por Harvard

University Press, de Londres, Inglaterra, 2011: Jorge Zahar Editor Ltda.

BENJAMIN, Antônio H.; MARQUES, Cláudia L.; BESSA, Leonardo R. Manual de Direito do Consumidor. $2^{\text {a }}$ ed.São Paulo, SP: Revista dos Tribunais, 2009.

BITTAR, Carlos Alberto. Revista de Direito do Consumidor 4/126-131, Instituto Brasileiro de Política e Direito do Consumidor: O controle da Publicidade -sancionamentos e mensagens enganosas e abusivas, São Paulo, RT, número especial, 1992.

BRAGA NETTO, Felipe Peixoto. Manual de direito do consumidor: à luz da jurisprudência do STJ. Salvador: Edições Juspodvim, 2014.

BRASIL. Código Brasileiro de Autorregulamentação Publicitária. Disponível em: http://www.conar.org.br. Acessado em: 10 de julho de 2018.

BRASIL. Constituição da República Federativa do Brasil. Brasília, DF: Senado Federal: Centro Gráfico, 1988.

BRASIL.Código Civil Brasileiro. Disponível em: http://www.planalto.gov.br. Acessado em: 10 de julho de 2018.

BRASIL. Lei no 8.069, de 13 de julho de 1990. Disponível em: http://www.planalto.gov.br. Acessado em: 10 de julho de 2018.

CANOTILHO, J. J. Gomes. Direito constitucional. 6. ed. Coimbra: Almedina, 1993.

CHAISE, Valéria Falcão. A Publicidade em face do Código de Defesa do Consumidor. São Paulo. Editora: Saraiva, 2001.

EFING, Antônio Carlos. Contratos e Procedimentos bancários à luz do Código de Defesa do Consumidor. São Paulo: Revista dos Tribunais, 1999.

FARIA, José Eduardo. O direito na economia globalizada, São Paulo: Malheiros, 2002.

Rev. de Direito, Globalização e Responsabilidade nas Relações de Consumo | e-ISSN: 2526-0030 | Porto Alegre | v. 4 | n. 2 | p. $129-144$ | Jul/Dez. 2018 
JACOBINA, Paulo Vasconcelos. Publicidade no direito do consumidor. Rio de Janeiro, Editora: Forense, 2002.

LOPES, Maria Elizabete Vilaça. Revista de Direito do Consumidor 1/149-183, Instituto Brasileiro de Política e Direito do Consumidor: O consumidor e Publicidade, São Paulo: RT, 1992.

MORAES, Paulo Valério Dal Pai. Código de defesa do consumidor: no contrato, na publicidade, nas demais práticas comerciais. 2 ed., Porto Alegre: Síntese, 2001. 